\title{
Physical methods for topical skin drug delivery: concepts and applications
}

\author{
Raquel Petrilli', Renata Fonseca Vianna Lopez ${ }^{1, *}$
}

\author{
${ }^{1}$ School of Pharmaceutical Sciences of Ribeirao Preto, University of Sao Paulo, Ribeirao Preto, SP, Brazil
}

\begin{abstract}
Topical drug delivery is an interesting approach to treat skin diseases and to avoid pain and low patient compliance in cases where a systemic delivery is required. However, the stratum corneum, which is the outermost skin layer, strongly protects the body from the entrance of substances, especially those hydrophilic. In this context, different physical methods have been studied to overcome the stratum corneum barrier and facilitate penetration of drugs into or through the skin. Among them, iontophoresis, low-frequency ultrasound and microneedles have been widely employed for transdermal drug delivery. More recently, they are also studied to aid in the treatment of dermatological disorders, such as skin tumors and inflammation. Basically, iontophoresis refers to the movement of charged and non-charged hydrophilic molecules through the skin due to the application of a low constant electric current and the contributions of electromigration and electroosmosis. In low-frequency ultrasound, cavitation is the main mechanism for skin permeabilization that consists on the formation of microbubbles that disorganize the stratum corneum. Microneedles are microprojections, minimally invasive, that can be designed with different lengths, materials and geometry to increase skin permeability. In this review, concepts, mechanisms and applications of these three physical methods will be presented and discussed with focus on their use in dermatological treatments. Moreover, comparative studies using different physical methods will be presented and also some clinical perspectives will be addressed.
\end{abstract}

Keywords: Iontophoresis. Sonophoresis. Microneedles. Skin delivery.

\section{INTRODUCTION}

Currently, there is a growing demand for therapies able to increase patient compliance, and thus topical administration of drugs aiming a topical or a systemic delivery are considered whenever possible (Lee et al., 2018). The possibility of delivering bioactive molecules through the skin represents an interesting alternative to oral or parenteral injection. This so called transdermal drug delivery bypasses the gastrointestinal tract and thus prevents the first-pass effect, is painless and allows selfadministration (Münch, Wohlrab, Neubert, 2016). Besides transdermal delivery, the skin is the main route of choice for the treatment of dermatological disorders and for local anesthesia (Goyal et al., 2016). Topical drug delivery can potentially eliminate the need of systemic administration of drugs, reduce the total drug dose required and thus

*Correspondence: R. F. V. Lopez. Faculdade de Ciências Farmacêuticas de Ribeirão Preto, Universidade de São Paulo. Av. Cafe s/n, 14040-903 - Ribeirao Preto, SP, Brazil. E-mail: rvianna@fcfrp.usp.br reduce adverse off-target effects (Goyal et al., 2016). Therefore, topical delivery is useful in the treatment of skin inflammations, photoaging, microbial and fungal infections and also skin cancer (Prow et al., 2016).

Topical or transdermal delivery requires that the drug overcomes the stratum corneum (SC), which is the main skin barrier, to reach the viable epidermis, where most of the cutaneous disorders are found, or the systemic circulation. For topical delivery, the main challenge is the balance between the penetration of the drug through the $\mathrm{SC}$ and its buildup in the skin to ensure suitable therapeutic concentration. Generally, small molecules can penetrate the SC easily or transpose the epidermis by the appendices. However, for high molecular weight molecules, such as peptides, siRNA and DNA, penetration into or through the skin remains a challenge (Goyal et al., 2016). This can be explained by the "500 Dalton Rule", which describes that a drug can penetrate the $\mathrm{SC}$ and be delivered through the skin if its molecular weight is less than 500 Daltons and if it is hydrophobic (Bos, Meinardi, 2000).

In this context, different approaches have been used 
to overcome the skin barrier and improve drug delivery. The use of chemical enhancers is by far the most explored. They are substances that are able to disturb skin-structure (Williams, Barry, 2004; Lane, 2013) resulting in several FDA- approved products for topical and transdermal delivery (Som, Yasir, Bhatia, 2012). However, it is difficult to select rationally a chemical penetration enhancer. They are drug-specific and the level of drug penetration increase is nonspecific; promotion through the skin of animals is usually much greater than that of humans; a complex concentration-dependent effect is usually observed; and the mechanisms of action are many (Lane, 2013; Lane et al., 2012). Moreover, in general, they are not able to increase the penetration of high molecular weight drugs in therapeutic concentrations (Wiliams, Barry, 2004).

With the advancement of biotechnology and the discovery of proteins and peptides with several therapeutic advantages, but unstable in biological fluids, transdermal administration has come to be considered as a strategy to their delivery. However, the high molecular weight and hydrophilicity of proteins is a serious impediment to their penetration through the SC. In this way, physical methods began to be studied.

Physical methods may be considered as an external force applied to a formulation, or to a drug delivery system, placed over the skin. This external force can disrupt the skin barrier or simply facilitate the delivery of the drug from the formulation with consequent increase in permeation of the drug. Among the various approaches available, some of them can be highlighted such as iontophoresis, which consists on the application of low intensity electric current (Gratieri et al., 2008), sonophoresis, with application of low-frequency ultrasound (Polat, Blankschtein, Langer, 2010) and microneedles, which are minimal invasive needle-like microprojections (Moffatt et al., 2017). Although these strategies have been extensively studied to facilitate transdermal drug delivery (Lee et al., 2018; Münch, Wohlrab, Neubert, 2017; Moffatt, 2017), in the last decade there is an increasing interest in their use for some dermatological treatments, such as skin cancer.

Herein, we aim to discuss the concepts involved in the cutaneous application of these three physical methods and their influence on topical skin treatments. For that, the major challenges in transposing the SC will be addressed taking into account the structure and physiology of the skin; the main mechanisms by which iontophoresis, sonophoresis and microneedles act to increase the penetration of drugs into the skin will be presented and discussed; the influence of the formulation upon which such methods are normally applied in targeting the drug to specific layers of the skin will be emphasized; and, finally, the potential of combining more than one physical method, in addition to clinical perspectives in the field will be presented and discussed.

\section{SKIN STRUCTURE AND PHYSIOLOGY}

The skin is the largest human organ, with approximately $15 \%$ of total body weight. It provides a robust barrier to toxic substances, UV radiation, pathogenic microorganisms and it is also responsible for preventing water and nutrients loss (Bos, Meinardi, 2000; Lane et al., 2012).

It comprises three major zones namely epidermis, dermis and subcutis. The epidermis is the outermost skin layer and is responsible for the skin color, texture and moisture. It is formed mainly by keratinocytes that proliferate for terminal differentiation resulting in the SC formation (Menon, 2002).

SC has a thin thickness, about $15-20 \mu \mathrm{m}$, but it represents the main skin barrier to the penetration of drugs. It is formed by dead corneocytes filled with keratin dipped into a lipid matrix containing ceramides, cholesterol and fatty acids, often referred by the "brick-and-mortar" structure (Nemes, Steinert, 1999; Schoellhammer, Blankschtein, Langer, 2014).

The other layers of the epidermis beyond the SC, referred as viable epidermis, are formed by epithelial cells that are able to renew the SC. Viable epidermis is approximately 50-100 $\mu \mathrm{m}$ thick and avascular consisting on basal, spinous and granulous layers. The majority of the cells are keratinocytes (about 95\%), but melanocytes, Langerhans cells and Merkel cells are also present (Menon, 2002; Prausnitz, Langer, 2008)

The epidermis is separated from the dermis by a thin basal membrane. The dermis is responsible for the nutritional support to the avascular epidermis, where collagen, elastin, blood vessels, sensory nerves and lymphatic vessels are present. Moreover, skin appendages, such as eccrine or apocrine sweat glands, sebaceous glands and hair follicles are originated in this layer. The dermis is formed mainly by fibroblasts, where collagen, elastin and other proteins are produced. Finally, the subcutis is the inner layer of the skin, composed by lipocytes, organized into fat lobules and separated by fibrous septae (LaiCheong, McGrath, 2013).

The skin acts as both a physical-mechanical and immunological barrier, able to avoid microorganism invasion and trigger an immune response. This immune response is caused by the production of anti-microbial peptides, that destruct gram-positive and gram-negative bacteria, fungi and some virus. Langerhans cells, present 
in the viable epidermis, act as antigen-presenting cells, presenting antigen-major histocompatibility complex (MHC) class II-complexes to T-cells. Furthermore, the dryness and barrier of the SC prevents growth of microorganisms on the skin (Venus, Waterman, McNab, 2011).

To penetrate the skin, most of the drugs take the intercellular pathway to transpose the SC, a tortuous way through the lipids that surround the corneocytes, although the transcellular route is also a possibility depending on drugs characteristics and formulation (Desai et al., 2013). Additionally, the presence of the appendices such as hair follicles associated to sebaceous glands and also the sweet glands can be an interesting path for drug delivery. Hair follicles are considered reservoir structures and an important penetration route for particle-based drug delivery. For instance, scalp hair follicles and dilated acne pores can allow the delivery of submicron particles (Vogt et al., 2016).

Therefore, designing a delivery system that helps the topically applied drug overcomes the SC, targeting it to specific layers of the skin at appropriate therapeutic concentrations and avoiding severe allergic responses is not an easy task. For that, physical methods have been studied.

\section{PHYSICAL METHODS FOR TOPICAL DRUG DELIVERY}

Different strategies for drug penetration enhancement can be used aiming to circumvent the SC barrier. Among them, occlusion, formulation optimization and physical methods can be used alone or combined (Grice et al., 2012). Physical methods can potentially increase the transport of macromolecules to the SC, enabling higher concentrations of drugs into deep skin layers (Gratieri et al., 2008). Thus, much effort has been conducted aiming for the transdermal drug delivery using physical methods. The most studied are iontophoresis, sonophoresis and microneedles. In the following subsections, these methods concepts and mechanisms will be presented. Recent research related to these methods for topical action will be discussed in the next section.

\section{Iontophoresis}

Iontophoresis consists on the application of low intensity electric current, usually up to $0.5 \mathrm{~mA} / \mathrm{cm}^{2}$, on biological membranes or tissues, such as the skin, to deliver therapeutic molecules aiming for topical or transdermal effect. The total iontophoretic flux of the drug refers to the sum of electromigration and electroosmosis contributions. Basically, the relative importance of each of these transport mechanisms is related to the physicochemical and electrical characteristics of the skin and the drug (Guy et al., 2000).

Briefly, an electric field is applied across the skin and distributed with the help of two electrodes, a positive one, the anode, and a negative one, the cathode (Figure 1). Preferably, an ionized drug is placed in a compartment in contact with the electrode of equal polarity. Thus, cationic drugs are placed in the anode compartment, whereas anionic ones are placed in the cathode. This is usually made because the application of an electric current in the skin results in cations migration toward the cathode and in anions migration in the opposite direction. This facilitated migration of ionized substances increases drugs transport through the skin.

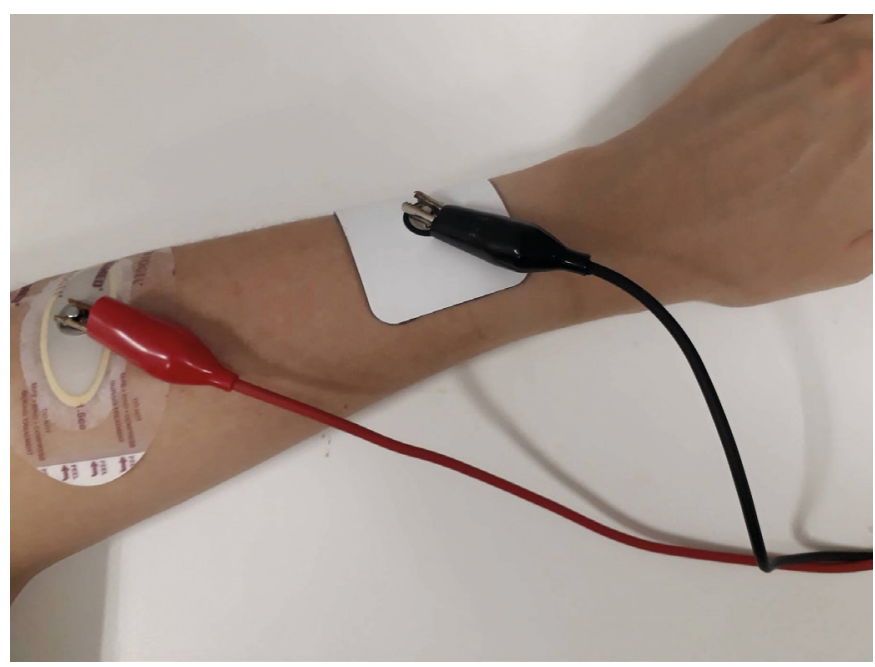

FIGURE 1 - Experimental setup for in vivo iontophoresis using Iogel $^{\circledR}$

The ordered movement of ions in the presence of an electric current applied to the skin is called electromigration. The contribution of electromigration $\left(\mathrm{J}_{\mathrm{EM}}\right)$ to the transport of an ionized drug depends on the skin area exposed to the current (A), ion charge (z), Faraday's constant ( $F=96,500$ $\mathrm{C} / \mathrm{moL}$ ), intensity of the electric current applied (I) and transport number (tx) (Equation I). The tx, in turn, depends on the mobility, charge and concentration of the ion (Kalia et al., 2004). The maximum transport ratio of a given ion occurs when the transport number for the ion is equal to 1 , i.e when the ion alone is able to carry $100 \%$ of the electric current through the skin.

$$
J_{E M}=\frac{1}{z A F} x t x I
$$


When the drug is uncharged at the $\mathrm{pH}$ of the formulation in which it is incorporated, its penetration by iontophoresis occurs with the contribution of electroosmosis. Electroosmosis refers to the flow of a volume of solvent and the movement of charges when an electric potential difference is applied to the skin (Kalia et al., 2004). Under physiological conditions, when the formulation placed on the skin has a $\mathrm{pH}$ close to 7.4, that solvent flow is greater from the anode than from the opposite direction. That happens because under these conditions the SC presents a residual negative charge due to ionization of the carboxylate groups associated with amino acid residues present therein. In this way, the transport of cations in direction to this negatively charged skin is favored over that of anions, making the skin permeselective to cations (Burnette, Ongpipattanakul, 1987). To maintain the electroneutrality of the system, a larger volume of water moves then toward the cathode and drag neutral substances present in the formulation, increasing drug skin permeation.

In order to optimize the iontophoretic transport, it is necessary, in this way, to adjust the formulation and the electrical parameters. The formulation should contain, in addition to the drug, the minimum of competitive ions and adequate $\mathrm{pH}$ to ensure that the electromigration and the electrosmosis occur preferentially in the same direction to increase the drug transport. The electrical parameters are related to the applied electric current density and the characteristics of the electrodes.

Different types of electrodes can be used, but usually $\mathrm{Ag} / \mathrm{AgCl}$ are employed because they avoid $\mathrm{pH}$ decreases. Also, their electrochemical reactions occur at lower voltage than that required for water electrolysis. Because water electrolysis results in the presence of protons that can compete with the cationic drug for the electric current, causing a reduction in drug delivery, the use of $\mathrm{Ag} / \mathrm{AgCl}$ electrodes that do not provoke it is a great advantage. Moreover, water electrolysis can reduce the $\mathrm{pH}$ of the formulation in contact with the anode, which would lead to skin burn and compromise drug stability. However, the use of $\mathrm{Ag} / \mathrm{AgCl}$ as electrodes requires the presence of a minimum of $\mathrm{Cl}^{-}$ions in the anode. The chlorides are necessary for proper oxidation reactions to occur in the anode. Briefly, the chloride ions oxidize the silver electrode resulting in silver chloride, which presents low solubility and is deposited at the electrode with the release of one electron. In the anode, a cation moves toward the skin or an anion leaves the skin and moves into the anodal chamber, thus electroneutrality is preserved. In the cathode, the electron released from the oxidation of the silver reduces the $\mathrm{AgCl}$ electrode, releasing chloride ion in the cathode compartment which is balanced by cations from the skin or by an anion migration toward the skin (Kalia et al., 2004).

Iontophoresis has been extensively studied for transdermal delivery of macromolecules. Among them, a variety of macromolecules had its permeation through the skin increased, such as peptides and proteins (Banga, Katakam, Mitra, 1995; Katikaneni et al., 2009), dextran sulfate (Badkar, Banga, 2002) and oligodeoxynucleotides (Kigasawa et al., 2011). In recent years its potential for topical treatment has been explored and will be presented in subsection "Physical methods for a topical treatment".

\section{Sonophoresis}

Sonophoresis, also named ultrasound or phonophoresis refers to the transport of drugs into and through the skin during or after the application of ultrasound. Ultrasonic waves are generated by an electric signal, which is amplified and sent to the horn of an ultrasonic transducer. When the electric signal reaches the horn, it is converted into a mechanical wave by piezoelectric crystals, located at the tip of the transducer, and is transmitted to a coupling medium. In topical application, the coupling medium is placed on the skin (Figure 2). The amplitude and the frequency with which the ultrasound is applied influence the oscillation of sound waves, resulting in the formation of different areas of rarefaction (low pressure) and compression (high pressure) in the medium, which cause different changes in skin permeability. Thus, amplitude and frequency are important parameters, where the amplitude refers to the ultrasound horn displacement during each half cycle and

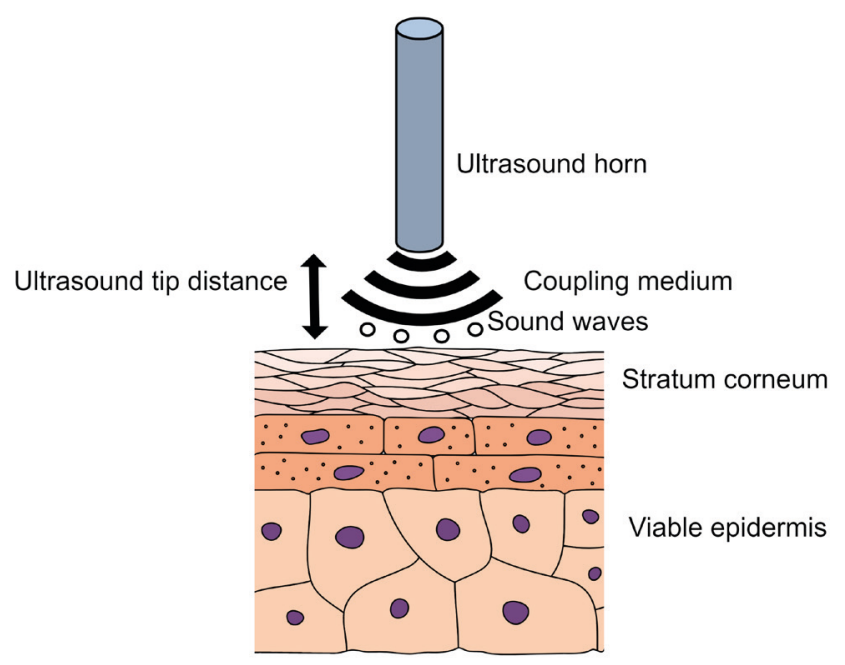

FIGURE 2 - Schematic representation of low frequency ultrasound application on skin surface. 
the frequency is related to the number of times that the tip is moved per second (Polat et al., 2011).

Ultrasound frequencies can range from $20 \mathrm{kHz}$ to $16 \mathrm{MHz}$, but usually low $(20-200 \mathrm{kHz})$ and medium ultrasound (0.2-1 MHz) frequencies, which possess high cavitational effects, are applied for drug delivery in the skin (Azagury et al., 2014). Cavitation is considered the main mechanism responsible for increased skin permeability, especially when using low frequency ultrasound (Polat et al., 2011).

Cavitation can be defined as the process by which air bubbles or cavities are formed in a medium in response to pressure variation caused by the movement of the sound wave. As shown in equation II, the radius of these bubbles is inversely proportional to the frequency of application of the ultrasound (Equation II).

$$
r=\frac{C}{f}
$$

Equation II

where: $r$ corresponds to the resonant radius of the cavitation bubble, f corresponds to the ultrasound frequency and $\mathrm{C}$ corresponds to a constant that is related to the properties of the coupling medium.

Thus, application to the skin of low frequency ultrasound results in larger bubbles than the application of the high frequency one. Application of ultrasound at frequencies above $0.6 \mathrm{MHz}$, for instance, results in bubbles with a radius less than $1 \mu \mathrm{m}$ (Polat et al., 2011), capable of entering the SC and inducing the disorganization of the lipidic layers, increasing the permeability of the skin. On the other hand, the application of low-frequency ultrasound, between 20 and $100 \mathrm{kHz}$, results in bubbles with a radius between 10 and $150 \mu \mathrm{m}$, which are too large to enter the SC (Polat et al., 2011). Cavitation in this case appears to occur predominantly in the coupling medium in contact with the horn, above the surface of the skin. In this case, experiments showed that the inertial (or transient) cavitation, which corresponds to the rapid and uncontrolled growth of the cavitation bubbles over several cycles of pressure, results in shock waves or microjets towards the skin (Tezel, Sens, Mitragotri, 2003; Tezel, Sens, Mitragotri, 2002b). In this way, low-frequency ultrasound eventually causes more changes to the skin, increasing its permeability more than high frequency ultrasound, especially for high-molecular weight drugs (Polat et al., 2011). Therefore, in this review we focus on the studies with low frequency ultrasound.

Different approaches are possible for sonophoresis application: the simultaneous treatment or the pretreatment. In the simultaneous treatment, the drug and ultrasound are applied at the same time and thus skin delivery is enhanced by the higher diffusion caused by structural modifications in the skin and also due to convection caused by ultrasound. In the pretreatment modality, ultrasound is applied by a short-time previously to the application of the drug. The main difference between them is that in the simultaneous treatment the drug transport decreases after ultrasound turning off and in the pretreatment the skin permeability is kept for some hours. Also, in the pretreatment modality there is no need for the use of an ultrasound device on the patient skin (Mitragotri, Kost, 2004).

The ultrasound-mediated skin drug delivery can be manipulated through changes in the application time and ultrasound parameters, leading to drug delivery locally, regionally or systemically (Polat, Blankschtein, Langer, 2010).

The influences of ultrasound horn distance from the skin, intensity and frequency were evaluated using different frequencies $(20 \mathrm{kHz}$ and $40 \mathrm{kHz})$. Basically, ultrasound was applied as a pretreatment and skin resistivity and aluminum foil pitting due to cavitation were monitored. An inverse relation between the distance of the horn from the skin and skin permeability was found. Furthermore, with higher ultrasound intensities, skin conductivity increased to a certain point and then dropped off (Terahara et al., 2002).

The main permeation pathway of substances through the skin pre-treated with the low-frequency ultrasound seems to be hydrophilic porous regions created with the treatment (Mitragotri, Kost, 2004). These regions are known as localized transport regions (LTRs) and were first demonstrated by Kushner, Blankschtein and Langer (2004). In this study, full-thickness porcine skin was pretreated with low-frequency ultrasound using sodium lauryl sulfate (SLS) as a coupling medium. After pretreatment, the skin was placed in contact with a hydrophilic dye, so that the LTRs were much more stained than the other regions of the skin and were visible to the naked eye. Calcein transport was measured through the LTRs and non-LTRs, which are regions that surround the LTRs. An 80-fold increase of calcein permeability was observed at the LTRs compared to non-LTRs. Also, both LTRs and non-LTRs revealed decreased electrical resistivity compared to untreated skin of 5000-fold and 170-fold, respectively, which suggests different intensities of skin structural modifications (Kushner, Blankschtein, Langer, 2004). In a subsequent study, the LTRs and nonLTRs properties were more deeply investigated. LTRs, non-LTRs and non-treated skin samples were submitted to different sonophoresis frequencies in the presence of SLS and related to the pore-radii. It has been shown that the pore radii of the LTRs, in addition to being larger than 
the non-LTR pore radii, increased as a function of the frequency decrease, whereas the pore radii of the nonLTRs were frequency independent. Although smaller than the LTR pores, non-LTRs showed greater permeability than untreated skin likely due to SLS perturbation (Polat et al., 2011).

In order to evaluate the skin transport of large or small hydrophilic molecules using sonophoresis, the permeability of mannitol, luteinizing hormone releasing hormone (LHRH), inulin and dextran were investigated using pig skin exposed to low-frequency ultrasound (58 kHz) (Tezel, Sens, Mitragotri, 2003). Using the modified porous pathway mathematical model (Tang et al., 2001), it was demonstrated that the permeability-resistivity for each permeant was modified according to molecule size. An inverse correlation between size and skin Permeability was found. Also, the tortuosity of the permeant into the skin depends on the size, where large molecules present a less tortuous pathway. In order to investigate the role of intracellular transport through lipid bilayers for small hydrophilic molecules (molecular weight under $400 \mathrm{Da}$ ) with moderate partition coefficient $\left(\mathrm{K}_{o}, \mathrm{~W}\right.$ between 0.1 and 1), the lipophilic pathway was incorporated into the porous pathway model (Tezel, Sens, Mitragotri, 2002a). Using different permeants, such as water, acetic acid, mannitol and corticosterone, authors found that for high skin resistivity the lipophilic pathway dominates the passive skin permeability; however, upon ultrasound exposure and the subsequent reduction in skin resistivity, the skin permeability is predominantly caused by the hydrophilic pathways. Also, for very hydrophilic permeants, like mannitol, the lipophilic pathways present negligible contribution.

\section{Microneedles}

Microneedles are minimally invasive tridimensional structures that circumvent the SC barrier through the formation of microscopic channels and thus guarantee local permeation of drugs into the skin (Prausnitz, 2004). These devices are formed by needle-like projections (Figure 3), in different shapes, usually in the range of micrometers (less than 1000 micrometers), that form aqueous micropores in the skin (Prausnitz, 2004; Wermeling et al., 2008).

These micro projections can be manufactured using different materials, such as metal, silicon, polymers, glass, ceramic, hydrogels, among others (Moffatt et al., 2017). Due to their small length and sharp aspect compared to hypodermic needles, they are able to penetrate the SC (50-900 $\mathrm{mm}$ in height) but present no contact with nerves

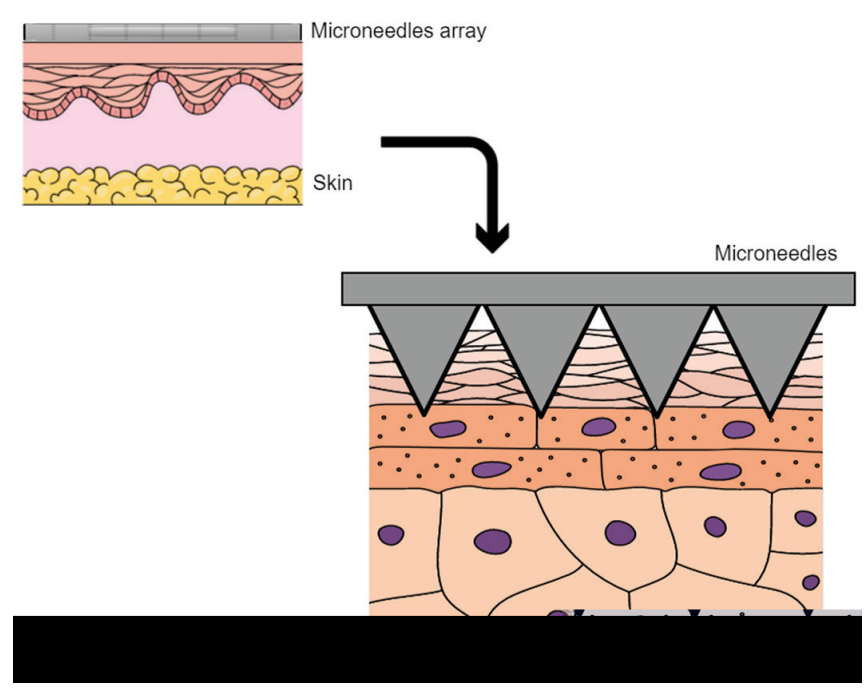

FIGURE 3 - Schematic representation of microneedles application on skin surface.

or blood vessels, resulting in a dramatic increase of drug or drug delivery systems penetration into the skin, without causing pain (Kaushik et al., 2001). Among the benefits of using microneedles for drug delivery, it can be mentioned the possibility to administer drugs with no pain and the possibility of delivering drugs to different skin layers (Moffatt et al., 2017).

When considering drug delivery based on microneedles different strategies can be applied. Hollow microneedles can promote therapeutics delivery with controlled release over the time through a single channel of a needle, whereas solid microneedles can be used as a pre-treatment to create pores in the skin, or the drug can be incorporated into the surface or the matrix of microneedles (Bhatnagar et al., 2017). For the hollow microneedles, which are usually manufactured using metals or silicon, the tip design is a critical step and is closely related to the needle resistance and insertion behavior, but also it needs to allow the continuous flow of the drug avoiding clogging (Bhatnagar et al., 2017). Solid microneedles are usually fabricated using laser micromachining and can be coated with drugs. Among them, dissolvable microneedles can be interesting, because no sharp waste is obtained (Ita, 2017).

The influence of pore formation and closure as a function of microneedles geometry has been investigated in some recent studies (Gupta et al., 2011; Brogden et al., 2012; Ghosh, Brogden, Stinchcomb, 2014; Römgens et al., 2014). For instance, different single solid microneedles with diameters ranging from 5 to $37 \mu \mathrm{m}$ were inserted into ex vivo human skin to monitor the force required for this insertion and the changes they caused on the surface of the skin. It was observed an average penetration 
depth at $1.5 \mathrm{~mm}$, and it was similar for different dip diameters but the process for skin penetration was different. The small diameters needles, such as the 5 $\mu \mathrm{m}$ one, were easily inserted and the force of insertion linearly increased with tip diameter, although the average penetration depth was similar for all needles diameters tested (Römgens et al., 2014). Another important issue addressed recently was the extent and duration of skin permeability enhancement caused by microneedles. A correlation between microneedles geometry and occlusion on skin resealing time was demonstrated. For instance, microneedles application without occlusion resulted in resealing after about $2 \mathrm{~h}$, whereas under occlusion, resealing occurred from 3 to $40 \mathrm{~h}$, depending on the geometry applied. Furthermore, longer microneedles and larger numbers were related with longer resealing times, demonstrating the role of microneedles geometry (Gupta et al., 2011).

Upon microneedles removal, the resealing is expected due to skin healing process, which reduces drugs delivery duration (Ghosh, Brogden, Stinchcomb, 2014). Some drugs, such as fluvastatin and diclofenac, demonstrated to have an important role on micropores closure delay (Brogden et al., 2012; Ghosh, Brogden, Stinchcomb, 2014). Fluvastatin acts as a 3-hydroxy-3methyl-glutaryl-CoA (HMGCoA) reductase inhibitor and thus reduces the synthesis of cholesterol that is an important component of the SC. To verify the hypothesis that fluvastatin could increase micropore lifetime, authors employed porcine skin for in vivo experiments and evaluated pores recovery and skin irritation. The skin resealed after about 30-45 min after occlusion removal and no irritation was observed (Ghosh, Brogden, Stinchcomb, 2014). In another study, diclofenac was tested for the same purpose. Briefly, authors discussed that the physiology related to micropores resealing in humans is not completely understood, but it might be related to subclinical local inflammation. Thus, diclofenac, a known non-steroidal anti-inflammatory molecule could delay this process. In order to test this hypothesis, impedance measurements, micropore closure kinetics and skin irritation were evaluated in volunteers from 1845 years old. The volunteers received one application of microneedles and daily topical treatment with diclofenac. The area under the admittance-time curve revealed slower pore resealing for those treated with diclofenac compared to the placebo group. Local erythema was not observed as confirmed using colorimetry measurements. These results suggest that diclofenac could enhance micropore lifetime with no significant irritation in human volunteers (Brogden et al., 2012).

\section{PHYSICAL METHODS FOR A TOPICAL TRE- ATMENT}

\section{Iontophoresis}

Iontophoresis has been successfully applied using different drugs for skin tumors treatment (Taveira, Nomizo, Lopez, 2009; Gelfuso et al., 2011; Souza et al., 2011; Taveira et al., 2014; Huber et al., 2015; Lemos et al., 2016; De Santana et al., 2017), head and neck cancers (Gratieri, Kalia, 2014), alopecia (Gelfuso et al., 2013; Gelfuso et al., 2015), local anesthesia (Rio-Sancho et al., 2017) and atopic dermatitis (Kigasawa et al., 2010).

For the topical treatment of skin cancer associated with iontophoresis, doxorubicin (DOX) has been incorporated into different delivery systems, such as a chitosan gel and solid lipid nanoparticles (SLN) (Taveira, Nomizo, Lopez, 2009; Taveira et al., 2014; Huber et al., 2015). The influence of the formulation on cutaneous penetration of DOX was investigated from saline and gels prepared with different polymers; hydroxyethylcellulose (HEC) and chitosan (Taveira, Nomizo, Lopez, 2009; Taveira et al., 2014; Huber et al., 2015). It was observed that iontophoresis of DOX-containing HEC gels increased the retention of the drug in SC compared to the DOX solution and that chitosan gel decreased such retention. The contribution of the electrosmotic flow to the overall iontophoretic transport was monitored and it was verified that both DOX and chitosan, positively charged substances, decreased the contribution of this flow. Interactions of these cationic molecules with negatively charged fatty acids present in $\mathrm{SC}$ were the explanation given for such behavior. The result of these interactions was that DOX iontophoresis from the chitosan gel favored the arrival of DOX in the viable epidermis due to the exchange of DOXSC interactions by chitosan-SC interactions, releasing DOX to diffuse to deeper layers of the skin. In addition, the cytotoxicity of these formulations in culture of melanoma cells (B16F10) with and without the application of low intensity electric current was investigated (Taveira, Nomizo, Lopez, 2009; Taveira et al., 2014; Huber et al., 2015). It was found that the application of iontophoresis at $0.5 \mathrm{~mA} / \mathrm{cm}^{2}$ increased DOX cytotoxicity. The application of the electric current in the absence of DOX did not cause significant cells death, suggesting that the increase in toxicity was caused by a greater permeabilization of the cell membrane in the presence of iontophoresis, increasing the uptake of DOX by the cells.

In an attempt to decrease the interactions of DOX with the SC, SLN containing DOX were prepared and characterized (Taveira et al., 2014; Huber et al., 
2015). SLN composed by stearic acid:lecithin:sodium taurodeoxycholate:water loaded with DOX presented a mean diameter and polydispersity of $175 \pm 26 \mathrm{~nm}$ and $0.28 \pm 0.04$, respectively and a negative zeta potential (Taveira et al., 2014). Anodal iontophoresis of these SLN increased 6-fold accumulation of DOX in the viable epidermis relative to passive administration (Taveira et al., 2014).

To evaluate the influence of iontophoresis on the SLN distribution in the skin, DOX was encapsulated in positively charged SLNs composed of cetyltrimethylammonium bromide (CTAB): stearic acid: monoolein: water. These SLNs, $136 \pm 17 \mathrm{~nm}$, were doubly labeled: in addition to DOX, a hydrophilic drug that emits fluorescence, it contained a lipophilic dye, a derivative of 4,4-difluoro-4-bora-3a,4a- diaza-s-indacene (BODIPY) as a marker of the nanoparticles itself (Huber et al., 2015). Confocal microscopy images taken after $1 \mathrm{~h}$ of anodal iontophoresis of these SLNs showed that the fluorescence of the two markers coincided after treatment and was concentrated, in the form of aggregates, at the base of the hair follicles, inside the skin. Thus, it was concluded that the encapsulation of DOX in SLN altered the drug physical-chemical characteristics and that DOX-loaded SLN iontophoresis created a reservoir of DOX in the hair follicles. Quantification of the accumulated DOX in the viable epidermis showed that iontophoresis increased approximately $40 \%$ the amount of DOX in the viable epidermis when compared to the passive penetration of DOX from the same SLN (Huber et al., 2015). This accumulation in viable epidermis resulted in an effective tumor growth reduction, followed by keratinization and cell death when the formulation was applied topically using iontophoresis in a xenograft animal model of squamous cell carcinoma (SCC), demonstrating the synergism between DOX-loaded SLN and iontophoresis to treat skin cancer.

Another commonly used treatment option for skin cancers is the photodynamic therapy (PDT). PDT consists on the application of photosensitizing agents that in the presence of oxygen and irradiation at specific wavelength, can potentially kill cancer cells based on the formation of reactive oxygen species (ROS) (Severyukhina et al., 2016). For this purpose, zinc phthalocyanine tetrasulfonic acid $\left(\mathrm{ZnPcS}_{4}\right)$ was incorporated into an HEC gel and this drug penetration was evaluated in vitro using porcine ear skin and in vivo both in healthy hairless mice and in human SCC (A431 cells) tumors induced in immunosuppressed mice (Souza et al., 2011; Lemos et al., 2016). $\mathrm{ZnPcS}_{4}$ was not able to reach viable epidermis when applied passively in vitro. The application of anodal iontophoresis on the HEC gel containing this negatively charged drug also did not increase the penetration of $\mathrm{ZnPcS}_{4}$ in the viable epidermis (Souza et al., 2011). Instead, when cathodal iontophoresis was applied, which means that HEC gel containing the drug was placed under the negative electrode, significant amounts of drug were found in viable epidermis. These results are related to the contributions of electromigration and electrosmotic fluxes involved in the transport of drugs by iontophoresis. The negatively charged drug placed in contact with the positive electrode, in the case of anodic iontophoresis, suffers only the contribution of the electrosmotic flow, which was not enough to overcome the attraction forces between the electrode and the drug and did not contribute significantly to cutaneous penetration of $\mathrm{ZnPcS}_{4}$. However, the addition of the drug to the negative electrode enabled the contribution of the electromigration, which allowed approximately $10 \mu \mathrm{g} / \mathrm{cm}^{2}$ and $55 \mu \mathrm{g} / \mathrm{cm}^{2}$ of the drug to accumulate in the viable epidermis after the iontophoresis of formulations containing, besides the drug, competitive ions $(90 \mathrm{mmol} / \mathrm{L} \mathrm{NaCl})$ and not containing these competitive ions, respectively. In vivo, in healthy skin of hairless mice, $15 \mathrm{~min}$ of cathodic iontophoresis of HEC gel containing only the drug was able to place in the viable epidermis 11 -fold more $\mathrm{ZnPcS}_{4}$ than $1 \mathrm{~h}$ of passive permeation (Souza et al., 2011). Recently, this formulation was evaluated in vivo using SCC xenograft animal model (Lemos et al., 2016). Briefly, PDT was performed immediately after $30 \mathrm{~min}$ of cathodal iontophoretic treatment with the formulationA 10 -fold enhancement in $\mathrm{ZnPcS}_{4}$ tumor penetration was observed compared to the passive delivery.

Furthermore, confocal microscopy studies made it possible to visualize the characteristic fluorescence of $\mathrm{ZnPcS}_{4}$ in deep regions of the tumor after iontophoresis, while the passive application allowed to visualize the drug only on the surface of the skin. Immediately after the application of iontophoresis, PDT treatment, performed using laser at $660 \mathrm{~nm}$, dose of irradiation of $100 \mathrm{~J} / \mathrm{cm}^{2}$ and irradiance of $48 \mathrm{~mW} / \mathrm{cm}^{2}$, reduced twice tumor growth compared to non-treated tumor (Lemos et al., 2016).

Alopecia treatment has also been investigated using iontophoresis. Minoxidil, a potent vasodilator, is used to topically treat androgenic alopecia in the form of commercially available ethanol and propylene glycol solutions to be applied twice daily. The potential of iontophoresis in targeting the release of a more soluble and potent derivative of minoxidil, the minoxidil sulfate (MXS), to the hair follicle, the focus of alopecia's treatment, was investigated (Gelfuso et al., 2013). First, the penetration of MXS into hair follicles from ethanolic solutions and Poloxamer hydrogels at different $\mathrm{pHs}$, 
5.5 and 3.5, was evaluated using the differential tape stripping technique (Gelfuso et al., 2013). After passive treatment using porcine ear skin, the amount of MXS in the SC and hair follicles was significantly higher for the gel compared to the ethanol-water solution, with reduced systemic exposure. Compared to passive administration, iontophoresis increased the accumulation of MXS in the follicular infundibulum. This accumulation was 3 -fold higher when anodic iontophoresis was performed on the MXS gel at $\mathrm{pH} 5.5$ instead of the gel at $\mathrm{pH} 3.5$. This $\mathrm{pH}$ effect can be explained by the negative charge of the skin at $\mathrm{pH} 5.5$ and the partial reversal of this charge at $\mathrm{pH} 3.5$. Although in anodic iontophoresis the contribution of the electromigration is high at $\mathrm{pH} 3.5$, when MXS is $90 \%$ ionized, the electrosmotic flow is in the opposite direction, from the cathode to the anode. At pH 5.5, on the other hand, electromigration and electroosmosis flows are in the same direction, both contributing to the penetration of MXS into the skin (Gelfuso et al., 2013).

Recently, the feasibility of administering MXS polymeric microparticles associated with iontophoresis for follicular targeting was evaluated (Gelfuso et al., 2015). Chitosan-based microparticles of $3 \pm 1.5 \mu \mathrm{m}$, zeta potential close to neutral $(6 \pm 5 \mathrm{mV})$ and drug loading efficiency of more than $80 \%$ were prepared by spray drier and dispersed in ethanol/water. The amount of MXS accumulated in the hair follicles was verified in vitro using pig ear skin and differential stripping technique. The iontophoresis of the microparticles was shown to increase the accumulation of MXS in the hair follicles over the iontophoresis of a solution of MXS at the same initial drug concentration $(2 \%)$ by almost 5 -fold after $6 \mathrm{~h}$ of treatment. Furthermore, the application of iontophoresis for $3 \mathrm{~h}$ followed by withdrawal of iontophoresis and continuous observation of the release of MXS from microparticles accumulated in the skin made it possible to observe the sustained release of MXS for the following $12 \mathrm{~h}$ of experiment (Gelfuso et al., 2015). Thus, iontophoresis of microparticles appears to be a promising strategy for the targeted and sustained treatment of cutaneous diseases that reach the hair follicles.

Topical iontophoresis can also be applied for local anesthesia. In a recent work, m-conotoxin CnIIIC (XEP), an antagonist of the sodium channel, was evaluated with the application of iontophoresis or passive administration in the skin. The experiments were carried out in vitro using both porcine and human skin. Upon passive administration, XEP was mainly accumulated in upper skin layers, as demonstrated by confocal microscopy studies and drug quantification in the skin. Iontophoresis treatments were performed using different electric current intensities, such as $0.1,0.3$ and $0.5 \mathrm{~mA} / \mathrm{cm}^{2}$ during 2 or
$4 \mathrm{~h}$. After the application of iontophoresis, it was observed that the highest intensity evaluated $\left(0.5 \mathrm{~mA} / \mathrm{cm}^{2}\right)$ resulted in the highest XEP deposition in the skin. Furthermore, it was observed increased XEP accumulation for longer iontophoresis treatment $(4 \mathrm{~h})$ compared to the shorter treatment (Río-Sancho et al., 2017). It is possible, in this way, to adjust the amount of drug desired in the skin by controlling the intensity of the electric current and the time of exposure.

Many other studies investigated the potential of iontophoresis for topical delivery of drugs. The results observed on the skin after application of iontophoresis in some topical formulations investigated in the last 7 years are summarized in Table I.

Thus, iontophoresis can be applied to different purposes since it can increase drug accumulation into deep skin layers and also promote a reservoir effect. The drug accumulated in higher concentrations can be used for improved cancer treatment, as well as for other skin applications such as atopic dermatitis, local anesthesia and also for the treatment of alopecia.

\section{Low frequency sonophoresis}

To date, there are few reports on the effect of low frequency sonophoresis for topical treatments. However, some interesting studies aiming to uncover the effect of LTRs on the distribution of drugs in the skin were reported. With them it is possible to begin to infer about the influence of ultrasound parameters and the formulation in targeting certain substances to specific layers of the skin. For instance, topical delivery of oligonucleotides (ODN) was assessed in vitro after a pretreatment of full-thickness pig skin using low frequency ultrasound at $20 \mathrm{kHz}, 2.4 \mathrm{~W} / \mathrm{cm}^{2}$ and $50 \%$ duty cycle $(5 \mathrm{~s}$ on $/ 5 \mathrm{~s}$ off $)$. The coupling medium used was a SLS aqueous solution at $1 \%$ and the skin was treated until resistivity reached $1 \mathrm{k} \Omega / \mathrm{cm}^{2}$. A solution of ODN labeled with FITC (ODN- FITC) at $5 \mu \mathrm{Ci} / \mathrm{mL}$ was then put in contact with the pretreated skin for $24 \mathrm{~h}$. The percentage of ODN-FITC in upper skin layers obtained after liquid scintillation analysis ranged from 0.5 to $5 \%$ of the donor concentration after 10 min of simultaneous treatment. ODN-FITC was largely localized in superficial skin layers, mainly in LTRs. The heterogeneous penetration resulted in LTRs that occupied about 5\% of the exposed skin area, as demonstrated by microscopy studies. The penetration of ODN into LTRs was also confirmed by immune-histochemical studies using an oligonucleotide with specificity for an antibody (Tezel et al., 2004).

In an attempt to increase the number and the homogeneity of LTRs formed in the skin, Schoellhammer 
TABLE I - Effect on the skin after application of iontophoresis in formulations developed in the last 7 years

\begin{tabular}{|c|c|c|c|}
\hline Formulation & Treatment & Iontophoresis Effect & Reference \\
\hline $\begin{array}{l}\text { Aqueous solution of ruthenium } \\
\text { nitrosyl complex (Ru-NO) and } \\
\text { the same complex containing } \\
\mathrm{H} 2 \mathrm{O} \text { in the place of NO } \\
\text { (Ru-aqueous) }\end{array}$ & $\begin{array}{l}\text { Anodal iontophoresis at } \\
0.5 \mathrm{~mA} / \mathrm{cm}^{2} \text { in healthy skin }\end{array}$ & $\begin{array}{l}\text { Increased } 15 \text { - and } 400 \text {-fold, for Ru-NO } \\
\text { and Ru-aqueous, respectively, the skin } \\
\text { permeation of Ru in vitro. Ru-aqueous } \\
\text { iontophoresis also resulted in accumulation } \\
\text { of Ru in the skin of an order of magnitude } \\
\text { greater than Ru-NO iontophoresis. }\end{array}$ & $\begin{array}{l}\text { (De Santana et al., } \\
\text { 2017) }\end{array}$ \\
\hline $\begin{array}{l}\text { Aqueous solution, hydrogel and } \\
\text { fast dissolving film containing } \\
\text { aciclovir amino acid ester } \\
\text { prodrugs (ACV-X, where } \\
\text { X = Arg, Ile or Val) }\end{array}$ & $\begin{array}{l}\text { Anodal Iontophoresis at } \\
0.25 \mathrm{~mA} / \mathrm{cm}^{2} \text { for } 10 \mathrm{~min} \text { in } \\
\text { healthy skin }\end{array}$ & $\begin{array}{l}\text { ACV species were found at deep skin } \\
\text { depths, basal epidermis and neighboring } \\
\text { layers, with similar deposition in full } \\
\text { thickness porcine and human skin. } \\
\text { Iontophoresis of the fast dissolving films } \\
\text { increased ACV accumulation in the skin } \\
\text { compared to the hydrogel. }\end{array}$ & (Chen et al., 2016) \\
\hline $\begin{array}{l}\text { Ovalbumin (OVA)- Liposomes } \\
\text { containing silver nanoparticles }\end{array}$ & $\begin{array}{l}\text { Cathodal iontophoresis at } \\
0.5 \mathrm{~mA} / \mathrm{cm}^{2} \text { in healthy skin }\end{array}$ & $\begin{array}{l}\text { In vitro, increased OVA penetration in } \\
\text { viable epidermis by } 92 \text {-fold. In vivo, } \\
15 \text { min of treatment in mice resulted in } \\
\text { antibodies production and differentiation of } \\
\text { immune- competent cells. }\end{array}$ & $\begin{array}{l}\text { (Bernardi et al., } \\
\text { 2016) }\end{array}$ \\
\hline $\begin{array}{c}\text { Hydrogels containing a } \\
\text { positively (TMPyP) or a } \\
\text { negatively (TPPS4) charged } \\
\text { porphyrins }\end{array}$ & $\begin{array}{c}\text { Anodal and cathodal } \\
\text { iontophoresis at } 0.5 \mathrm{~mA} / \mathrm{cm}^{2} \\
\text { in healthy skin }\end{array}$ & $\begin{array}{c}\text { In vitro, the positively charged TMPyP } \\
\text { permeated more the skin than the } \\
\text { negatively charged TPPS4. In vivo, in } \\
\text { Wistar rats, TPPS4 accumulated in the } \\
\text { upper layers of the skin, whereas TMPyP } \\
\text { was observed in deeper layers. }\end{array}$ & $\begin{array}{l}\text { (Gelfuso et al., } \\
\text { 2011) }\end{array}$ \\
\hline $\begin{array}{c}\text { Naked siRNA } \\
\text { (fluorescent labeled) }\end{array}$ & $\begin{array}{c}\text { Cathodal iontophoresis } \\
\text { at } 0.3 \mathrm{~mA} / \mathrm{cm}^{2} \text { in atopic } \\
\text { dermatitis induced with OVA } \\
\text { to stimulate IL-10 mRNA } \\
\text { expression }\end{array}$ & $\begin{array}{l}\text { In vitro, naked siRNA accumulated in the } \\
\text { epidermis but not in the dermis. Rat model } \\
\text { of atopic dermatitis was treated with anti- } \\
\text { IL- } 10 \text { siRNA, resulting in } 73 \% \text { reduction } \\
\text { in the level of IL- } 10 \text { mRNA using } 1 \mathrm{~h} \\
\text { iontophoresis application. }\end{array}$ & $\begin{array}{l}\text { (Kigasawa et al., } \\
\text { 2010) }\end{array}$ \\
\hline
\end{tabular}

et al. (2012) evaluated the effect of the association of the low- frequency ultrasound with the high-frequency one. The authors hypothesized that the application of the second ultrasound, oriented parallel to the surface of the skin, would nucleate a greater amount of cavitation bubbles, which would collapse in response to the acoustic waves generated by the low-frequency ultrasound, oriented perpendicular to the surface of the skin, thus increasing the formation of LTRs. Indeed, this association increased the area of skin covered by LTRs, from approximately 5 to $10 \%$ (Tezel et al., 2002) to about $30 \%$ (Schoellhammer et al., 2012). In addition, the LTRs generated were considered more permeable than those formed when skin pretreatment was performed only with low-frequency ultrasound (Schoellhammer et al., 2015).

Recently, the influence of hydrogels as coupling medium and their impact in LTRs distribution after treatment with $20 \mathrm{kHz}$ ultrasound was studied (Pereira,
Ramos, Lopez, 2017). Porcine skin was ultrasound treated in vitro using cationic, anionic and non-ionic hydrogels with similar viscosities. The anionic hydrogel (Carbopol), which lost its viscosity during the ultrasound application, resulted in the lowest percentage of LTRs. On the other hand, the non-ionic Poloxamer gel, which presents a thermosensitive behavior with increased viscosity as a function of increase in the temperature that occurs during the application of the ultrasound, was the one that presented the highest percentage of LTRs. Using the hydrogels as coupling media, LTRs extension was at least 3 -fold greater than those observed using the traditional ultrasound treatment with SLS, suggesting a correlation between viscosity increase and LTRs formation (Pereira, Ramos, Lopez, 2017).

Penetration of the chemotherapeutic drug, DOX, in the skin with hydrogels with different zeta potential was also evaluated. For positively charged DOX, the cationic coupling hydrogel medium reduced the amount 
of the drug recovered from viable epidermis by 2.8 -fold, whereas using the anionic hydrogel medium, the amount of DOX retained in the SC increased by approximately 4-fold. As a result, authors suggested that low-frequency ultrasound can potentially target ionized drugs to specific skin layers, by variations in the charge of the coupling medium (Pereira, Ramos, Lopez, 2017).

The low and medium frequency ultrasound have been studied in association with different molecules for the treatment of inflammation (Cohen et al., 2015; Chan, Tong, $\mathrm{Ng}, 2016$ ). Cohen et al (Cohen et al., 2015), for instance, investigated the anti-inflammatory effect of betamethasone topical administration combined to 20 min of low-frequency ultrasound $(20 \mathrm{kHz}$, simultaneous application of the drug and ultrasound) for arthritis treatment. Arthritis, induced in rats by carrageenan injection, was monitored by paw swelling and indirectly by measuring the glycolytic activity. The results indicated that ultrasound combined to betamethasone improved the anti-inflammatory effect compared to the negative control, the drug or ultrasound administered alone. In another recent study, fish oil was applied topically using a mediumfrequency ultrasound, at $1 \mathrm{MHz}$. The rats were divided in groups consisted of topical placebo vaseline (group I), topical fish oil (group II), therapeutic ultrasound (group III) or therapeutic ultrasound combined with fish oil (group IV). Vaseline containing fish oil was used as coupling medium for the group IV, whereas pure vaseline was used for group III. The rats were treated during 2 or 4 weeks and by the end of the treatments, the animals were sacrificed and the Achilles tendons were exposed and subject to tests for structural stiffness, ultimate tensile strength and energy absorption capacity. After 4 weeks of treatment, ultrasound group and the combination group (fish oil with ultrasound) presented improvement in the ultimate tensile strength, whereas the fish oil group and the combination group demonstrated better structural stiffness. Thus, only the combination group presented improved ultimate tensile strength and structural stiffness (Chan, Tong, Ng, 2016).

\section{Microneedles}

Microneedles have been studied associated with PDT to increase the penetration of photosensitizers or their precursors in the skin, as can be seen in Table II. Photosensitizers are usually large molecules with unfavorable physicochemical characteristics for topical delivery, such as very high hydrophilicity or lipophilicity. Nonetheless, their topical administration is desirable to make possible a topical PDT. Upon systemic administration of photosensitizers, serious side effects can occur, such as prolonged photosensitivity. Topical administration avoids systemic exposure, restricting the photosensitizer penetration to the target. In this context, increasing their skin permeation using microneedles has emerged as a promising strategy (Kearney et al., 2014). Indeed, in vivo experiments have been shown a homogeneous distribution of photosensitizers in the skin after the treatment with microneedles (Kolde, Rowe, Meffert, 2013), a reduction of skin cancer growth (Jain, Lee, Gill, 2016) and the disappearance of precancerous lesions (Kolde, Rowe, Meffert, 2013) (Table II).

Another usually reported application is the use for topical pain management (Macedo et al., 2017). Since some anesthetic drugs present rapid clearance from dermis or blood, strategies to overcome this hurdle and thus prolong anesthetic effect are promising. In a recent study, polymeric microneedles were dip-coated with lidocaine and adjuvants, such as clonidine and its analogs, guanfacine and apraclonidine, aiming a prolonged anesthetic effect (Zhang et al., 2012). Briefly, microneedles were molded using a liquid crystalline polymer and the produced arrays were coated, using the dip-coating method, with the anesthetic drug lidocaine containing the adjuvants. After drying, the microneedles surface was observed in order to verify coating depth and uniformity. The devices were evaluated in vivo using porcine skin and assessed by the quantification of local anesthetic concentration in the skin. The prolonged analgesia effect observed was imputed to the improved skin retention of lidocaine compared to the control without the adjuvants verified using skin biopsies (Zhang et al., 2012).

\section{Comparative studies and combination methods}

Comparative studies between the physical methods in relation to the increase that they induce in the cutaneous permeation of specific drugs have been performed in a punctual way. Comparisons were made between iontophoresis and sonophoresis, mainly aimed at transdermal drug penetration. For instance, in a recent work, the effect of passive skin delivery, iontophoresis and sonophoresis were compared for the transdermal delivery of peptide-dendrimer conjugates of ketoprofen (Hedge et al., 2017). First, ketoprofen was covalently tethered to mildly cationic $(2+$ or $4+)$ peptide dendrimers, resulting in different types of conjugates (different dendrimer sequence, $[\mathrm{M}+\mathrm{H}]^{+}$peaks and molecular weight). Afterwards, the passive, anodic iontophoresis and low-frequency sonophoresis (applied for $30 \mathrm{~min}$ at the amplitude of $\sim 30$ and power output of 7-8 W/ $\mathrm{cm}^{2}$, simultaneous treatment) methods were employed 
TABLE II - Recent studies describing the use of microneedles for the treatment of skin conditions

\begin{tabular}{|c|c|c|c|c|}
\hline $\begin{array}{l}\text { Therapeutic } \\
\text { application }\end{array}$ & Drug & Microneedle treatment & Microneedles effect & References \\
\hline Topical anesthesia & Lidocaine & $\begin{array}{l}\text { Polymeric microneedles } \\
\text { coated with the drug and } \\
\text { adjuvants. Array with } 316 \\
\text { microneedles (height of } \\
\text { approximately } 500 \mu \mathrm{m} \text { ) }\end{array}$ & $\begin{array}{c}\text { Prolonged } \\
\text { analgesia effect, with improved } \\
\text { skin retention of lidocaine } \\
\text { compared to the control without the } \\
\text { adjuvants. }\end{array}$ & $\begin{array}{c}\text { (Zhang et al., } \\
\text { 2012) }\end{array}$ \\
\hline $\begin{array}{c}\text { Genetic skin } \\
\text { diseases and skin } \\
\text { cancers }\end{array}$ & Plasmid DNA & $\begin{array}{c}\text { Coated microneedles, } \\
\text { fabricated using } \\
75 \mu \mathrm{m} \text { thick stainless-steel } \\
\text { sheets }\end{array}$ & $\begin{array}{l}\text { Using excised human skin } \\
\text { explants, microneedles required } \\
\text { low force to be inserted. The } \\
\text { reporter gene expression was } \\
\text { improved in epidermal cells. } \\
\end{array}$ & $\begin{array}{c}\text { (Pearton et al., } \\
\text { 2012) }\end{array}$ \\
\hline $\begin{array}{l}\text { Actinic keratoses } \\
\text { and Bowen's } \\
\text { disease / PDT }\end{array}$ & $\begin{array}{l}\text { 5-aminolaevulinic } \\
\text { acid (ALA) in } \\
\text { nanoemulsion }\end{array}$ & $\begin{array}{l}\text { Pre-treatment with } \\
\text { commercial microneedles } \\
\text { (rollers) }\end{array}$ & $\begin{array}{l}\text { In human, in vivo, homogenous } \\
\text { distribution and intense } \\
\text { fluorescence of the lesions after } 3 \mathrm{~h} \\
\text { of drug application was observed. } \\
\text { Lesions regressed completely after } \\
2 \text { to } 4 \text { treatments. }\end{array}$ & $\begin{array}{l}\text { (Kolde, Rowe, } \\
\text { Meffert, 2013) }\end{array}$ \\
\hline Antioxidant & $\begin{array}{l}\text { Quercetin } \\
\text { incorporated } \\
\text { or not in lipid } \\
\text { microparticles }\end{array}$ & $\begin{array}{l}\text { Silicon microneedle arrays } \\
\left(36 \text { microneedles } / \mathrm{cm}^{2} ;\right. \\
\text { microneedle height, } \\
200 \mu \mathrm{m})\end{array}$ & $\begin{array}{l}\text { In porcine skin, in vitro, significant } \\
\text { increase in the amount of quercetin } \\
\text { retained in the SC and viable } \\
\text { epidermis when microneedles } \\
\text { were applied associated to } \\
\text { microparticles. No improvement } \\
\text { was observed for microneedles } \\
\text { application without } \\
\text { the microparticles. }\end{array}$ & $\begin{array}{c}\text { (Paleco et al., } \\
\text { 2014) }\end{array}$ \\
\hline Skin tumors / PDT & ALA & $\begin{array}{l}\text { Coated microneedle patch } \\
\text { with } 57 \text { needles. }\end{array}$ & $\begin{array}{c}\text { In vitro, in porcine skin, } \\
\text { fluorescence -induced by ALA } \\
\text { was observed in deeper skin layers } \\
(\sim 480 \mu \mathrm{m}) \text { than the control }(\sim 150 \\
\mu \mathrm{m}) \text {. } \\
\text { In vivo, tumor induced in mice } \\
\text { presented a growth reduction of } \\
57 \% \text {. }\end{array}$ & $\begin{array}{c}\text { (Jain, Lee, Gill, } \\
\text { 2016) }\end{array}$ \\
\hline Analgesia & $\begin{array}{l}15 \text {-deoxy- } \Delta^{12,14} \text { - } \\
\text { prostaglandin } J_{2}\end{array}$ & $\begin{array}{l}\text { Pretreatment with } \\
\text { microneedle array } \\
\text { containing } 57 \text { needles } \\
(700 \mu \mathrm{m} \text { in length and } \\
200 \mu \mathrm{m} \text { in width each). }\end{array}$ & $\begin{array}{c}\text { In rats, reduction in } \\
\text { nociception compared to intra } \\
\text { temporomandibular join injection } \\
\text { was observed, besides anti- } \\
\text { inflammatory effect, with reduced } \\
\text { levels of tumor necrosis factor- } \alpha \\
\text { and interleukin-1 beta }\end{array}$ & $\begin{array}{c}\text { (Macedo et al., } \\
\text { 2017) }\end{array}$ \\
\hline
\end{tabular}

in mouse skin, $\mathrm{pH} 7.4$, both in vitro and in vivo and the permeated ketoprofen was quantified. Iontophoresis was able to dramatically increase the amount of dendrimericketoprofen after $6 \mathrm{~h}$, compared to ketoprofen alone. For passive and sonophoresis treatments, ketoprofen alone presented the highest permeation, with substantial increase for sonophoresis, although higher permeation was also observed for dendrimeric-ketoprofen compared to the passive delivery. Amounts of about 68, 97 and $168 \mu \mathrm{g} /$ $\mathrm{cm}^{2}$ were delivered passively $(24 \mathrm{~h})$, by iontophoresis $(6 \mathrm{~h})$ and after sonophoresis (30 min) application, respectively (Hedge et al., 2017).

Iontophoresis has been compared with microneedles pre-treatment aiming the topical application of methyl 
aminolevulinate (MAL) in ex vivo human skin (OsmanPonchet et al., 2017). Abrasion of the skin using 10 passages of a commercial pad (Ambu ${ }^{\circledR}$ Unilect ${ }^{\mathrm{TM}} 2121 \mathrm{M}$ ) followed by the application of a MAL cream $\left(100 \mathrm{mg} / \mathrm{cm}^{2}\right)$ for $2.5 \mathrm{~h}$ was also performed for comparison. Microneedles effect was evaluated after pretreating the skin with 8 rolling repetitions of a commercial roller (Dermaroller ${ }^{\circledR}$ HC 902), followed by the application of MAL cream $\left(100 \mathrm{mg} / \mathrm{cm}^{2}\right)$ for $2.5 \mathrm{~h}$ while anodal iontophoresis was performed at 1 $\mathrm{mA} / \mathrm{cm}^{2}$ through a MAL cream $\left(20 \mathrm{mg} / \mathrm{cm}^{2}\right)$ for $1.5 \mathrm{~h}$. It was observed a 103-fold increase in MAL accumulation in the skin after pad pretreatment, 4-fold increase after microneedling and 1.8-fold increase after iontophoresis, compared to intact skin. However, it is important to emphasize that the results obtained should not be taken as a generalization that one method is superior to another. As discussed in the previous sections, skin penetration of drugs by physical methods is a complex process. It depends at least on drug physicochemical properties, the intended use, electrical or sonochemical parameters and formulation characteristics.

To increase the penetration of drugs into the skin, some studies evaluate the combination between physical methods or between them and chemical penetration enhancers. The studies presented below are some examples.

The penetration pathway of lanthanum nitrate tracer in viable epidermis was evaluated using the chemical enhancer oleic acid associated with sonophoresis (Lee et al., 2010). Briefly, a lanthanum nitrate solution was prepared and toluidine blue was added in order to visualize the LTRs. Tracer solutions were applied to the dorsal region of hairless mice and ultrasound at $25 \mathrm{kHz}$ was applied for $5 \mathrm{~min}$. The solution was changed every 20 $\mathrm{s}$ by turning off the ultrasound equipment. In this study, different groups were analyzed, such as passive skin penetration, the effect of low-frequency ultrasound alone, low-frequency ultrasound combined to tape stripped skin and low-frequency ultrasound combined to the chemical enhancer oleic acid. Thus, for physical enhancement evaluation, low-frequency ultrasound was applied to a previously tape stripped skin, whereas for chemical enhancement, low-frequency ultrasound was applied after treatment with oleic acid and completely removal of it from skin surface. The results demonstrated that combined treatment with oleic acid or with tape stripped skin caused a significantly increase in lanthanum nitrate penetration into viable epidermis, reaching the stratum basal layer, whereas other treatments resulted in the accumulation of the tracer in upper skin layers (Lee et al., 2010). A possible mechanism for the improvement on skin penetration of the lanthanum nitrate resulting from the association between sonophoresis and the penetration enhancer is the ability of low-frequency ultrasound to increase the penetration of oleic acid through LTRs. Amphiphilic penetration enhancers present an even better synergism with ultrasound because of the adsorption of their monomers to the surface of the cavitation bubbles, resulting in deposition into the skin (Polat et al., 2012).

\section{Clinical perspectives}

A variety of recent studies illustrated the potential of the clinical use of physical methods for topical delivery of drugs. For instance, a comparative trial involving more than 40 patients evaluated the effect of ablative fractional laser-primed photodynamic therapy (AFLPDT) with MAL associated or not to iontophoresis for actinic keratosis treatment in the face and scalp (Choi et al., 2017). For this purpose, patients were randomly divided into groups using AFL-PDT with iontophoresis for $2 \mathrm{~h}$ incubation (10 $\mathrm{min}$ iontophoresis plus $110 \mathrm{~min}$ of contact of a MAL cream, under occlusion) (group A), conventional AFL-PDT for $2 \mathrm{~h}$ (group B) or $3 \mathrm{~h}$ (group C). It was observed efficacy of approximately $90 \%$ for groups $\mathrm{A}$ and $\mathrm{C}$, whereas about $70 \%$ was found for group B after 3 months of treatment. After 12 months, groups A and C also showed comparable results, that were more effective than those obtained for group B. As a conclusion, authors suggest that iontophoresis assisted treatment has potential to decrease the incubation time with comparable results to non-assisted iontophoresis (Choi et al., 2017).

Some devices that function assisted by iontophoresis are already available in the market. For instance, the LidoSite ${ }^{\circledR}$ Topical System from Vyteris was the first iontophoresis device to receive the US Food and Drug Administration (FDA) approval on 2004. It is used for lidocaine and epinephrine dermal analgesia in intact skin (Gratieri et al., 2008; Kalia et al., 2004). Basically, LidoSite is composed by a disposable pre-filled patch, a re-usable controller and a flexible connector (Alkilani, McCrudden, Donnelly, 2015).

For the treatment of focal palmar and plantar hyperhidrosis the use of tap water and iontophoresis is considered by many dermatologists as the first line of treatment for sweat relief. Currently, some devices are approved by FDA for this purpose. The R.A. Fischer, from R. A. Fischer Co, and the Drionic, from General Medical Company (Pariser, Ballard, 2014), are example of them. Other devices and gel-based patches are commercially available for use in hospitals, such as Phoresor ${ }^{\mathbb{R}}$ and Iogel ${ }^{\mathbb{R}}$ from Iomed Inc. Ionsys ${ }^{\circledR}$, an electrically- assisted patch 
for fentanyl release, was withdraw from the USA market recently, in June 2017, due to a business decision of The Medicines Company (Ionsys, 2018).

Some reports showed the application of lowfrequency sonophoresis with clinical potential in humans for localized drug delivery. In one of these reports, a topical steroid, betamethasone 17-valerate, commonly used as anti-inflammatory drug was applied in healthy volunteers in different regions of the forearms, divided in topical steroid application with $1 \mathrm{~h}$ occlusion (zone 1), 2 h occlusion (zone 2 ) and massage (zone 3 ). Randomized forearms received sonophoresis treatment $(36 \mathrm{kHz}$, $2.72 \mathrm{~W} / \mathrm{cm}^{2}$ ) in the pulsed mode for $5 \mathrm{~min}$. Considering the 15 volunteers included, vasoconstriction was more pronounced for zone 2, especially when ultrasound was applied (Maruani et al., 2010).

The potential of low-frequency sonophoresis for therapeutic delivery of drugs resulted in clinical trials. Recently, a clinical trial has started recruiting and about 120 participants are expected. The project is an interdisciplinary collaboration to treat chronic wounds using ultrasound. Basically, low frequency ultrasound at $20 \mathrm{kHz}$ and $<100 \mathrm{~mW} / \mathrm{cm}^{2}$ will be applied using a portable lightweight device. It is expected the acceleration of chronic wounds closure (Clinical Trials, 2017). In 2013, a pilot study with 20 patients has been conducted and the potential of applying the ultrasound has been demonstrated. The subjects were treated with ultrasound at different frequencies $(20 \mathrm{kHz}$ or $100 \mathrm{kHz})$ for 15 or 45 min per session for up to four treatments. It was observed complete healing for all five patients treated at a frequency of $20 \mathrm{kHz}$ for 15-minute intervals (Samuels et al., 2013). The potential for ultrasound application in health care has motivated companies to develop ultrasound based devices. For instance, Nanovibronix has designed different products that transmit low-frequency ultrasound using flexible materials for different health applications, such as PainShield ${ }^{\circledR}$, WoundShield ${ }^{\mathrm{TM}}$, UroShield ${ }^{\mathrm{TM}}$ and NGShield ${ }^{\mathrm{TM}}$ (Nanovibronix, 2018).

Microneedles have also been investigated with potential clinical application. In a recent study, clinical application of retinoic acid-loaded microneedle patches was performed in volunteers aiming the treatment of seborrheic keratosis or senile lentigo (Hirobe et al., 2017). In that occasion, retinoic acid-loaded microneedles patch was applied for $6 \mathrm{~h}$ in the lesion site once a week, totalizing four applications. The skin was monitored for irritation score and blood samples were collected to evaluate systemic exposure. The efficacy was evaluated by desquamation and whitening at the lesion site. The results indicated desquamation of the $\mathrm{SC}$ in four volunteers as a result of SC turn over without local or systemic severe side effects, demonstrating its feasibility for seborrheic keratosis or senile lentigo topical therapy.

In this context, both industry and academia are dedicated for the development of microneedles arrays. To date, the commercially available devices are aimed to be used in painless vaccination. Micronjet ${ }^{\mathbb{R}}$ (Nanopass Tachnology Ltd.), for instance, is a silicon microneedle device, single-use, aiming the transdermal delivery of vaccines and drugs (Alkilani, McCrudden, Donnelly, 2015). Recently, inactivated influenza vaccine was delivered using a microneedle patch in a randomized phase 1 trial. The study evaluated immunocompetent adults, aged from 18- 49 years, naïve to the 2014-2015 influenza vaccine. The participants were divided in four groups and received a single dose of the vaccine by different routes of administration, such as using the influenza microneedle patch or intramuscular injection. Other groups included the placebo patch and also self-administrated influenza microneedle patch. The microneedles patchs were well tolerated and preferred by patients compared to intramuscular injection. Also, serological titers obtained after influenza microneedle patch application, either applied by a health-care professional or selfadministered by the patient, were similar to those obtained after intramuscular injection (Rouphael et al., 2017). Furthermore, many studies employ Dermaroller ${ }^{\mathbb{B}}$ for skin delivery of drugs (Kolde, Rowe, Meffert, 2013; OsmanPonchet et al., 2017).

\section{CONCLUSION}

Topical skin delivery of drugs is currently being employed for different purposes such as skin cancers treatment, inflammatory diseases, alopecia and topical anesthesia.

Different drugs have been studied but usually passive skin delivery is not suitable due to drug molecular size and physicochemical properties that hamper their delivery to deep skin layers. Currently, physical methods are available both in lab bench and in the clinic and thus different devices have been developed and applied successfully. Iontophoresis, low frequency ultrasound and microneedles were presented herein and their fundaments and mechanisms were discussed. Also, some recent examples have been shown, demonstrating that all the physical methods discussed were able to increase the penetration depth of drugs compared to the passive delivery and thus improved the retention of different drugs in viable epidermis. Some devices are already available in the market particularly for transdermal drug delivery. 
For topical delivery, although many studies were already performed, systemic exposure is a concern. Formulation strategies, such as the use of delivery systems can potentially increase the amount of drug retained in viable epidermis and avoid systemic side effects.

\section{ACKNOWLEDGEMENTS}

This work was supported by the São Paulo Research Foundation (FAPESP grants \#2017/05930-7 and \#2014/22451-7). Figures 2 and 3 were designed using the Software MindTheGraph.

\section{REFERENCES}

Alkilani AZ, McCrudden MTC, Donnelly RF. Transdermal drug delivery: Innovative pharmaceutical developments based on disruption of the barrier properties of the stratum corneum. Pharmaceutics. 2015;7(4):438-70.

Azagury A, Khoury L, Enden G, Kost J. Ultrasound mediated transdermal drug delivery. Adv Drug Deliv Rev. 2014;72:12743.

Badkar AV, Banga AK. Electrically enhanced transdermal delivery of a macromolecule. J Pharm Pharmacol. 2002;54(7):907-12.

Banga AK, Katakam M, Mitra R. Transdermal iontophoretic delivery and degradation of vasopressin across human cadaver skin. Int J Pharm. 1995;116(2):211-6.

Bernardi DS, Bitencourt C, da Silveira DSC, da Cruz ELCM, Pereira-da-Silva MA, Faccioli LH, et al. Effective transcutaneous immunization using a combination of iontophoresis and nanoparticles. Nanomed Nanotechnol, Biol Med. 2016;12(8):2439-48.

Bhatnagar S, Dave K, Vamsi V, Venuganti K. Microneedles in the clinic. J Contr. 2017;260:164-82.

Bos JD, Meinardi MMHM. The 500 Dalton rule for the skin penetration of chemical compounds and drugs. Exp Dermatol. 2000;9(3):165-9.

Brogden NK, Milewski M, Ghosh P, Hardi L, Crofford LJ, Stinchcomb AL. Diclofenac delays micropore closure following microneedle treatment in human subjects. J Control Release. 2012;163(2):220-9.
Burnette RR, Ongpipattanakul B. Characterization of the permselective properties of excised human skin during iontophoresis. J Pharm Sci. 1987;76(10):765-73.

Chan KOW, Tong HHY, Ng GYF. Topical fish oil application coupling with therapeutic ultrasound improves tendon healing. Ultrasound Med Biol. 2016;42(12):2983-9.

Chen Y, Zahui T, Alberti I, Kalia YN. Cutaneous biodistribution of ionizable, biolabile aciclovir prodrugs after short duration topical iontophoresis : Targeted intraepidermal drug delivery. Eur J Pharm Biopharm. 2016;99:94-102.

Choi S-H, Kim T-H, Song K-H. Efficacy of iontophoresisassisted ablative fractional laser photodynamic therapy with short incubation time for the treatment of actinic keratosis: 12-month follow-up results of a prospective, randomised, comparative trial. Photodiagnosis Photodyn Ther. 2017;18:10510 .

Clinical Trials. 2017. NCT03041844. https://clinicaltrials.gov/ ct2/show/study/NCT03041844.

Cohen G, Natsheh H, Sunny Y, Bawiec CR, Touitou E, Lerman MA, et al. Enhanced therapeutic anti-inflammatory effect of betamethasone on topical administration with low-frequency, low-intensity $(20 \mathrm{kHz}, 100 \mathrm{~mW} / \mathrm{cm} 2)$ ultrasound exposure on carrageenan-induced arthritis in a mouse model. Ultrasound Med Biol. 2015;41(9):2449-57.

De Santana DCAS, Dias K, Souza JG, Ogunjimi AT, Souza MC, Silva RS, et al. NO exchange for a water molecule favorably changes iontophoretic release of ruthenium complexes to the skin. Molecules. 2017;22(1):pii:E104.

Desai PR, Shah PP, Hayden P, Singh M. Investigation of follicular and non-follicular pathways for polyarginine and oleic acid-modified nanoparticles. Pharm Res. 2013;30(4):1037-49.

Gelfuso GM, Barros MAO, Delgado-Charro MB, Guy RH, Lopez RFV. Iontophoresis of minoxidil sulphate loaded microparticles, a strategy for follicular drug targeting? Colloids Surf B Biointerfaces. 2015;134:408-12.

Gelfuso GM, Gratieri T, Delgado-Charro M, Guy RH, Lopez R. Iontophoresis- targeted, follicular delivery of minoxidil sulfate for the treatment of alopecia. J Pharm Sci. 2013;102(5):9-11. 
Gelfuso GM, Gratieri T, Souza JG, Thomazine JA, Lopez RFV. The influence of positive or negative charges in the passive and iontophoretic skin penetration of porphyrins used in photodynamic therapy. Eur J Pharm Biopharm. 2011;77(2):24956.

Ghosh P, Brogden NK, Stinchcomb AL. Fluvastatin as a micropore lifetime enhancer for sustained delivery across microneedle-treated skin. J Pharm Sci. 2014;103(2):652-60.

Goyal R, Macri LK, Kaplan HM, Kohn J. Nanoparticles and nano fi bers for topical drug delivery. J Control Release. 2016;240:77-92.

Gratieri T, Kalia YN. Targeted local simultaneous iontophoresis of chemotherapeutics for topical therapy of head and neck cancers. Int J Pharm. 2014;460(1-2):24-7.

Gratieri T, Martins G, Fonseca R, Lopez V. Princípios básicos e aplicação da iontoforese na penetração cutânea de fármacos. Quim Nova. 2008;31(6):1490-8.

Grice JE, Prow TW, Kendall MAF, Roberts MS. Electrical and physical methods of skin penetration enhancement. Transdermal Top Drug Deliv Princ Pract. 2012;43-65.

Gupta J, Gill HS, Andrews SN, Prausnitz MR. Kinetics of skin resealing after insertion of microneedles in human subjects. J Control Release. 2011;154(2):148-55.

Guy RH, Kalia YN, Delgado-Charro MB, Merino V, Lopez A, Marro D. Iontophoresis: Electrorepulsion and electroosmosis. J Control Release. 2000;64(1-3):129-32.

Hegde AR, Rewatkar PV, Manikkath J, Tupally K, Parekh HS, Mutalik S. Peptide dendrimer-conjugates of ketoprofen: Synthesis and ex vivo and in vivo evaluations of passive diffusion, sonophoresis and iontophoresis for skin delivery. Eur J Pharm Sci. 2017;102:237-49.

Hirobe S, Otsuka R, Iioka H, Quan Y, Kamiyama F, Asada H, et al. Clinical study of a retinoic acid-loaded microneedle patch for seborrheic keratosis or senile lentigo. Life Sci. 2017;168:24-7.

Huber LA, Pereira TA, Ramos DN, Rezende LCD, Emery FS, Sobral LM, et al. Topical Skin Cancer Therapy Using Doxorubicin-Loaded Cationic Lipid Nanoparticles and lontophoresis. J Biomed Nanotechnol. 2015;11(11):1975-88.

Ionsys. http://www.ionsys.com/index.html. Accessed: June 2018.
Ita K. Dissolving microneedles for transdermal drug delivery: Advances and challenges. Biomed Pharmacother. 2017;93:111627.

Jain AK, Lee CH, Gill HS. 5-Aminolevulinic acid coated microneedles for photodynamic therapy of skin tumors. J Control Release. 2016;239:72-81.

Kalia YN, Naik A, Garrison J, Guy RH. Iontophoretic drug delivery. Adv Drug Deliv Rev. 2004;56(5):619-58.

Katikaneni S, Badkar A, Nema S, Banga AK. Molecular charge mediated transport of a $13 \mathrm{kD}$ protein across microporated skin. Int J Pharm. 2009;378(1-2):93-100.

Kaushik S, Hord AH, Denson DD, McAllister DV, Smitra S, Allen $\mathrm{MG}$, et al. Lack of pain associated with microfabricated microneedles. Anesth Analg. 2001;92(2):502-4.

Kearney M, Brown S, Mccrudden MTC, Brady AJ, Donnelly RF. Potential of microneedles in enhancing delivery of photosensitising agents for photodynamic therapy. Photodiagnosis Photodyn Ther. 2014;11(4):459-66.

Kigasawa K, Kajimoto K, Hama S, Saito A, Kanamura K, Kogure K. Noninvasive delivery of siRNA into the epidermis by iontophoresis using an atopic dermatitis- like model rat. Int J Pharm. 2010;383(1-2):157-60.

Kigasawa K, Kajimoto K, Nakamura T, Hama S, Kanamura $\mathrm{K}$, Harashima $\mathrm{H}$, et al. Noninvasive and efficient transdermal delivery of CpG-oligodeoxynucleotide for cancer immunotherapy. J Control Release. 2011;150(3):256-65.

Kolde G, Rowe E, Meffert H. Effective photodynamic therapy of actinic keratoses and Bowen's disease using microneedle perforation. Br J Dermatol. 2013;168(2):450-2.

Kushner J, Blankschtein D, Langer R. Experimental demonstration of the existence of highly permeable localized transport regions in low-frequency sonophoresis. J Pharm Sci. 2004;93(11):2733-45.

Lai-Cheong JE, McGrath JA. Structure and function of skin, hair and nails. Medicine (Baltimore). 2013;41(6):317-20.

Lane ME, Santos P, Watkinson AC, Hadgraft J. Passive skin permeation enhancement. In: Benson, HAE, Watkinson AC (editors). Transdermal and topical drug delivery: principles and practice. Hoboken, NJ: Wiley; 2012. p. 23-42. 
Lane ME. Skin penetration enhancers. Int J Pharm. 2013;447(12):12-21.

Lee H, Song C, Baik S, Kim D, Hyeon T, Kim D-H. Deviceassisted transdermal drug delivery. Adv Drug Deliv Rev. 2018;127:35-45.

Lee SE, Choi KJ, Menon GK, Kim HJ, Choi EH, Ahn SK, et al. Penetration pathways induced by low-frequency sonophoresis with physical and chemical enhancers: iron oxide nanoparticles versus lanthanum nitrates. J Invest Dermatol. 2010;130(4):106372.

Lemos CN, De Souza JG, Simão PS, Lopez RFV. Iontophoresis improved growth reduction of invasive squamous cell carcinoma in topical photodynamic therapy. PLoS One. 2016;11(1):1-13.

Macedo CG, Jain AK, Franz-Montan M, Napimoga MH, Clemente-Napimoga JT, Singh H. Microneedles enhance topical delivery of 15-deoxy- $\Delta 12,14$ - prostaglandin $\mathrm{J} 2$ and reduce nociception in temporomandibular joint of rats. J Control Release. 2017;265:22-9.

Maruani A, Boucaud A, Perrodeau E, Gendre D, Giraudeau B, Machet L. Low- frequency ultrasound sonophoresis to increase the efficiency of topical steroids: A pilot randomized study of humans. Int J Pharm. 2010;395(1-2):84-90.

Menon GK. New insights into skin structure: Scratching the surface. Adv Drug Deliv Rev. 2002;54(Suppl 1):S3-17.

Mitragotri S, Kost J. Low-frequency sonophoresis: A review. Adv Drug Deliv Rev. 2004;56(5):589-601.

Moffatt K, Wang Y, Raj Singh TR, Donnelly RF. Microneedles for enhanced transdermal and intraocular drug delivery. Curr Opin Pharmacol. 2017;36:14-21.

Münch S, Wohlrab J, Neubert RHH. Dermal and transdermal delivery of pharmaceutically relevant macromolecules. Eur J Pharm Biopharm. 2017;119:235-42.

Nanovibronix. https://www.nanovibronix.com/. Accessed June 2018.

Nemes Z, Steinert PM. Bricks and mortar of the epidermal barrier. Exp Mol Med. 1999;31(1):5-19.
Osman-Ponchet AH, Gaborit A, Bianchi C, Linget J, Claire E. Pretreatment of skin using an abrasive skin preparation pad, a microneedling device or iontophoresis improves absorption of methyl aminolevulinate in ex vivo human skin. Photodiagnosis Photodyn Ther. 2017;S1572:30372-1.

Paleco R, Vu SR, Crean AM, Moore A, Scalia S. Enhancement of the in vitro penetration of quercetin through pig skin by combined microneedles and lipid microparticles. Int J Pharm. 2014;472(1-2):206-13.

Pariser DM, Ballard A. Iontophoresis for palmar and plantar hyperhidrosis. Dermatol Clin. 2014;32(4):491-4.

Pearton M, Saller V, Coulman SA, Gateley C, Anstey AV, Zarnitsyn V, et al. Microneedle delivery of plasmid DNA to living human skin: Formulation coating, skin insertion and gene expression. J Control Release. 2012;160(3):561-9.

Pereira TA, Ramos DN, Lopez RFV. Hydrogel increases localized transport regions and skin permeability during low frequency ultrasound treatment. Sci Rep. 2017;7:44236.

Polat BE, Blankschtein D, Langer R. Low-frequency sonophoresis: application to the transdermal delivery of macromolecules and hydrophilic drugs. Expert Opin Drug Deliv. 2010;7(12):1415-32.

Polat BE, Deen WM, Langer R, Blankschtein D. A physical mechanism to explain the delivery of chemical penetration enhancers into skin during transdermal sonophoresis Insight into the observed synergism. J Control Release. 2012;158(2):250-60.

Polat BE, Figueroa PL, Blankschtein D, Langer R. Transport pathways and enhancement mechanisms within localized and non-localized transport regions in skin treated with lowfrequency sonophoresis and sodium lauryl sulfate. J Pharm Sci. 2011;100(2):512-29.

Polat BE, Hart D, Langer R, Blankschtein D. Ultrasoundmediated transdermal drug delivery: Mechanisms, scope, and emerging trends. J Control Release. 2011;152(3):330-48.

Prausnitz MR, Langer R. Transdermal drug delivery. Nat Biotechnol. 2008;26(11):1261-8.

Prausnitz MR. Microneedles for transdermal drug delivery. Adv Drug Deliv Rev. 2004;56(5):581-7. 
Prow TW, Grice JE, Lin LL, Faye R, Butler M, Becker W, et al. Nanoparticles and microparticles for skin drug delivery. Adv Drug Deliv Rev. 2011;63(6):470-91.

Río-Sancho S, Cros C, Coutaz B, Cuendet M, Kalia YN. Cutaneous iontophoresis of $\mathrm{m}$ - conotoxin CnIIIC - A potent $\mathrm{Na}$ V 1.4 antagonist with analgesic, anaesthetic and myorelaxant properties. Int J Pharm. 2017;518:59-65.

Römgens AM, Bader DL, Bouwstra JA, Baaijens FPT, Oomens CWJ. Monitoring the penetration process of single microneedles with varying tip diameters. J Mech Behav Biomed Mater. 2014;40:397-405.

Rouphael NG, Paine M, Mosley R, Henry S, McAllister DV, Kalluri $\mathrm{H}$, et al. The safety, immunogenicity, and acceptability of inactivated influenza vaccine delivered by microneedle patch (TIV-MNP 2015): a randomised, partly blinded, placebocontrolled, phase 1 trial. Lancet. 2017;390(10095):649-58.

Samuels JA, Weingarten MS, Margolis DJ, Zubkov L, Sunny Y, Bawiec CR, et al. Low-frequency $(<100 \mathrm{kHz})$, lowintensity $(<100 \mathrm{~mW} / \mathrm{cm}(2))$ ultrasound to treat venous ulcers: a human study and in vitro experiments. J Acoust Soc Am. 2013;134(2):1541-7.

Schoellhammer C, Blankschtein D, Langer R. Skin permeabilization for transdermal drug delivery: recent advances and future prospects. Expert Opin Drug Deliv. 2014;11(3):393407.

Schoellhammer CM, Polat BE, Mendenhall J, Maa R, Jones B, Hart DP, et al. Rapid skin permeabilization by the simultaneous application of dual-frequency, high-intensity ultrasound. J Control Release. 2012;163(2):154-60.

Schoellhammer CM, Srinivasan S, Barman R, Mo SH, Polat BE, Langer R, et al. Applicability and safety of dual-frequency ultrasonic treatment for the transdermal delivery of drugs. J Control Release. 2015;202:93-100.

Severyukhina AN, Petrova NV, Smuda K, Terentyuk GS, Klebtsov BN, Georgieva R, et al. Photosensitizer-loaded electrospun chitosan-based scaffolds for photodynamic therapy and tissue engineering. Colloids Surf B Biointerfaces. 2016;144:57-64.

Som I, Yasir M, Bhatia K. Mohd. Yasir Status of surfactants as penetration enhancers in transdermal drug delivery. J Pharm Bioallied Sci. 2012;4(1):2-9.
Souza JG, Gelfuso GM, Simão PS, Borges AC, Lopez RF V. Iontophoretic transport of zinc phthalocyanine tetrasulfonic acid as a tool to improve drug topical delivery. Anticancer Drugs. 2011;22(8):783-93.

Tang H, Mitragotri S, Blankschtein D, Langer R. Theoretical description of transdermal transport of hydrophilic permeants: Application to low-frequency sonophoresis. J Pharm Sci. 2001;90(5):545-68.

Taveira SF, Nomizo A, Lopez RF V. Effect of the iontophoresis of a chitosan gel on doxorubicin skin penetration and cytotoxicity. J Control Release. 2009;134(1):35-40.

Taveira SF, Santana DCAS, Araújo LMPC, Marquele-Oliveira F, Nomizo A, Lopez RFV. Effect of Iontophoresis on topical delivery of doxorubicin-loaded solid lipid nanoparticles. J Biomed Nanotechnol. 2014;10(7):1382-90.

Terahara T, Mitragotri S, Kost J, Langer R. Dependence of lowfrequency sonophoresis on ultrasound parameters; distance of the horn and intensity. Int J Pharm. 2002;235(1-2):35-42.

Tezel A, Dokka S, Kelly S, Hardee GE, Mitragotri S. Topical delivery of anti- sense oligonucleotides using low-frequency sonophoresis. Pharm Res. 2004;21(12):2219-25.

Tezel A, Sens A, Mitragotri S. Description of transdermal transport of hydrophilic solutes during low-frequency sonophoresis based on a modified porous pathway model. J Pharm Sci. 2003;92(2):381-93.

Tezel A, Sens A, Mitragotri S. Incorporation of lipophilic pathways into the porous pathway model for describing skin permeabilization during low-frequency sonophoresis. J Control Release. 2002a;83(1):183-8.

Tezel A, Sens A, Mitragotri S. Investigations of the role of cavitation in low- frequency sonophoresis using acoustic spectroscopy. J Pharm Sci. 2002b;91(2):444-53.,

Tezel A, Sens A, Tuchscherer J, Mitragotri S. Synergistic effect of low-frequency ultrasound and surfactants on skin permeability. J Pharm Sci. 2002;91(1):91-100.

Venus M, Waterman J, McNab I. Basic physiology of the skin. Surgery. 2011;29(10):471-4. 
Vogt A, Wischke C, Neffe AT, Ma N, Alexiev U, Lendlein A. Nanocarriers for drug delivery into and through the skin - Do existing technologies match clinical challenges? J Control Release. 2016;242:3-15.

Wermeling DP, Banks SL, Hudson DA, Gill HS, Gupta J, Prausnitz MR, et al. Microneedles permit transdermal delivery of a skin-impermeant medication tohumans. Proc Natl Acad Sci. 2008;105(6):2058-63.
Williams AC, Barry BW. Penetration enhancers. Adv Drug Deliv Rev. 2004;56(5):603-18.

Zhang Y, Siebenaler K, Brown K, Dohmeier D, Hansen K. Adjuvants to prolong the local anesthetic effects of coated microneedle products. Int J Pharm. 2012;439(1-2):187-92. 